\title{
Reducing error: benign abnormalities mimicking malignancy when reporting scans of patients with known malignancy
}

\author{
S Jenkins ${ }^{*}, G$ Joseph \\ From International Cancer Imaging Society Meeting and 15th Annual Teaching Course (ICIS 2015) \\ London, UK. 5-7 October 2015
}

\section{Learning objectives}

To improve the ability to accurately report CT and MRI by learning to recognise benign findings that may mimic malignant pathology in the setting of scans performed on patients with known malignancy.

\section{Content organisation}

$\mathrm{CT}$ and MR images will be displayed demonstrating benign abnormalities that are easily misinterpreted as metastases, recurrent tumour or residual tumour in patients with known malignancy. Examples of benign findings will be displayed next to the corresponding malignant abnormalities to demonstrate the potential error.

\section{Conclusion}

The ability to accurately differentiate between benign and malignant disease can be challenging and can contribute to reporting discrepancies even amongst experienced radiologists. This can be especially demanding when imaging patients with known malignancy and is a concern for general and specialist radiologists. Being aware of abnormalities that mimic malignancy will help to increase the accuracy of $\mathrm{CT}$ and MR reports and ensure the correct treatment plans are implemented.

Submit your next manuscript to BioMed Central and take full advantage of:

- Convenient online submission

- Thorough peer review

- No space constraints or color figure charges

- Immediate publication on acceptance

- Inclusion in PubMed, CAS, Scopus and Google Scholar

- Research which is freely available for redistribution 